\title{
Identifying and Preventing Cardiac Risk Factors from Fetal Life
}

\author{
Lawrence M. Benedict' ${ }^{1}$ Deeksha Sarma' ${ }^{1}$ Achintya Moulick ${ }^{1,2}$, Randy Stevens ${ }^{1,2}$, Vicki Mahan* \\ 'Drexel University College of Medicine, PA, USA \\ ${ }^{2}$ Department of Pediatric Cardiothoracic Surgery, St. Christopher's Hospital for Children, Philadelphia, PA, USA
}

Article Info

\section{Article Notes}

Received: May 22, 2018

Accepted: July 26, 2018

\section{${ }^{*}$ Correspondence:}

Dr. Vicki L. Mahan, MD, The Heart Center, St. Christopher's Hospital for Children, 160 Erie Avenue, Philadelphia, PA 19134, USA; Telephone No: (215)-427-4814; Fax (215)-4273860; Email: mahan_vicki@yahoo.com.

(c) 2018 Mahan V. This article is distributed under the terms of the Creative Commons Attribution 4.0 International License.

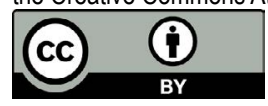

\section{Keywords}

Cardiovascular Disease

Atherosclerosis

Familial Hypercholesterolemia

Dyslipidemia

Pediatric Cholesterol

Metabolic Syndrome

\section{Abstract}

Cardiac risk factors in childhood are often overlooked in clinical practice, however cardiac risk factors can start before the child is even born. Maternal factors including diet, genetics, and smoking during gestation can all impact the long-term cardiac health of the offspring. Atherosclerosis starts as early as fetal life and can continue to develop in children with risks including high cholesterol. Current guidelines for screening of cholesterol in children, while improving in recent years, still allows years of damage to accumulate before identifying those at risk. Additionally, intervention for cholesterol and other known risks in children and adolescents are often avoided or started later than necessary for optimal cardiac health. Non-pharmacological approaches like diet and exercise for cholesterol and health management can be implemented very early in life, while many pharmacological options are approved for use in certain conditions as early as ages 8 to 10 . Combating cardiac disease reaching endemic levels in the developed world will take an aggressive approach in management starting with identification early in life and utilizing the appropriate tools available, both medical and lifestyle.

\section{Introduction}

Cardiovascular Disease is the number one underlying cause of death worldwide ${ }^{1}$. Risk factors like diabetes, obesity, and dyslipidemia are endemic in the United States population. Obesity rates among children is as high as $16.9 \%$ in the United States ${ }^{2}$. One survey had found that an estimated $53 \%$ of the US population had some form of dyslipidemia including $27 \%$ with high LDL-C and $30 \%$ with high triglyceride levels ${ }^{3}$. In efforts to detect dyslipidemia during childhood, in 2011 the American Academy of Pediatrics has prescribed screening at ages 9-11 and 17-21 years of age proposing diet and exercise changes for initial treatment ${ }^{4}$. There is increasing evidence showing that atherosclerosis and other cardiac risk factors can begin in fetal and neonatal life $e^{5,6}$. It is becoming increasingly clear that there is a need for earlier diagnosis and intervention to ensure optimal cardiac health outcomes.

\section{Risk Factors from the Mother}

\section{Maternal Genetics}

Much concern has been placed on the maternal lipid level impact on the neonatal cholesterol and triglyceride levels. Evidence suggests that maternal cholesterol is transported to the placenta via ABCA1 and ABCG1 transporters ${ }^{7}$. These transporters have been found to be so important to fetal development that they are even 
being investigated as a target for treatment of gestational Smith-Lemli-Opitz syndrome, a disorder of fetal synthesis of cholesterol ${ }^{8}$. Maternal lipid profile is also known to have an important impact on the gestational size of the neonate ${ }^{9}$.

Maternal ethnicity is known to have an important impact on maternal gestational cholesterol levels ${ }^{10}$. Though hyperlipidemia can be as a result of dietary and other environmental factors, genetics typically plays a primary role in the phenotype of the individual. Dyslipidemias are classified using the Fredrickson classification, and can be monogenic or polygenic in nature. Fredrickson Type II or Familial hypercholesterolemia is the most common genetic dyslipidemia stemming from mutations in LDLR, APOB, PCSK9, and others ${ }^{11}$. In fact, genetic disorders are known to vary by ethnicity. Familial hypercholesterolemia is believed to have a prevalence as high as 1:250 in the United States general population (higher than 1:500 previously reported) but 1:211 in African Americans and 1:414 in Mexican Americans ${ }^{12}$. More broadly, other ethnicities show even larger extremes with a subset of French Canadians have prevalence of 1:154 and South African Jews have a rate as high as $1: 67^{13,14}$. As indicated above, maternal cholesterol is known to be transported across the placenta which may then impact the fetus ${ }^{8}$.

A combined increase in cholesterol and triglyceride levels in pregnant mothers has been shown to be a predictor of preterm labor ${ }^{15}$. Further, a low birth weight (which can be caused by premature birth as a result of preterm labor) can lead to complications during adult ages, including chronic diseases such as hypertension, type 2 diabetes mellitus, metabolic disease, and cardiovascular disease ${ }^{16}$. More generally, preterm infants have had significantly higher rates of being overweight and obese, and have had higher incidence of endocrine disorders ${ }^{17}$.

More directly, maternal hypercholesterolemia enhances fatty streak formation in fetal arteries of some spontaneously aborted fetuses ${ }^{6}$. While some fatty streak lesions in newborns regressed by as much as $64 \%$ during childhood, others progressed at an accelerated rate, particularly lesions in the aortic arch and abdominal aorta $^{18}$. In rabbits, increased maternal cholesterol via diet was sufficient to increase the fatty streak formation while cholesterol lowering treatment decreased this formation ${ }^{19}$.

Further complicating the issue of maternal hyperlipidemia, control of cholesterol with statins and some other medications have been contraindicated during pregnancy due to teratogenicity. Reviews of pregnancies with statin exposures showed nervous system and limb developmental abnormalities in the offspring ${ }^{20}$. One study showed promising results in improving glycemic control, reducing maternal cholesterol levels, and associated risks to the fetus, using phytosterols ${ }^{21}$.

\section{Diabetes mellitus in mother}

A CDC study found that as many as $9.2 \%$ of pregnancies were affected by gestational diabetes mellitus ${ }^{22}$. Additionally, of all pregnancies impacted by diabetes, preexisting diabetes mellitus in pregnancy has increased from $10 \%$ to $21 \%$ of all diabetic pregnancies ${ }^{23}$. Pregnancies in women with diabetes mellitus can result in an increased risk of certain morbidities affecting both mother and child. These include congenital malformations and morbidities, and obstetrical complications. One study found that, though women with diabetes mellitus type 1 may have planned their pregnancies and attempted to prepare well for their pregnancies, there were still morbidities that occurred disproportionate to the general population; complications included congenital malformations, macrosomia, preeclampsia, and hypoglycemia ${ }^{24}$. In fact, children born to mothers with diabetes were found to have an increased rate of congenital malformations with a significant representation of cardiac malformations ${ }^{25}$.

Another study showed that macrosomic children born to diabetic or obese mothers had a significantly higher risk of developing metabolic syndrome during their childhood. Increased rates of insulin resistance and presence of multiple components of metabolic syndrome were present in these patients by age 11, putting them at a further increased risk for developing cardiovascular disease and diabetes $^{26}$.

\section{Maternal Smoking}

Atherosclerotic lesions of coronary arteries can be seen in prenatal and infancy periods, and these lesions are highly associated with maternal cigarette smoking ${ }^{27}$. Many of the lesions in the coronary vessels progress to juvenile atherosclerotic plaques with characteristic proliferation of the smooth muscle cells of the tunica media. The vessel wall thickening associated with these plaques decreased the lumen diameter by up to $30-40 \%{ }^{28}$.

Active maternal smoking during pregnancy has been associated with negative changes in birth weight ${ }^{29,30}$. Decreased birth weight alone has been linked to additional risk for cardiovascular disease ${ }^{16}$. Smoking also increased the perinatal death rate by nearly $20 \%$ in one epidemiology study $^{30}$. Active maternal smoking was linked with significant decrease in antioxidant capacity in the neonate whereas both active and passive maternal smoking was associated with worse total oxidant status and oxidative stress inde ${ }^{29}$. Unsurprisingly then, paternal smoking was also significantly linked to atherosclerotic lesions in the coronary vessels of neonates ${ }^{28}$.

\section{Maternal Drinking}

Fetal alcohol exposure has long been associated 
with Fetal Alcohol Syndrome after discovery of the syndrome in 1973 characterized by "craniofacial, limb, and cardiovascular defects associated with prenatal-onset growth deficiency and developmental delay." ${ }^{31}$. Since that time there have been many different mechanisms by which the fetus may be impacted including multiple mechanisms involving alterations to the fetal lipid metabolism. In chickens, fetal exposure to alcohol caused reduced free cholesterol levels ${ }^{32}$. In zebrafish, fetal exposure to alcohol also impacted signaling molecules utilizing cholesterol, including blocking covalent modification of Sonic Hedgehog by cholesterol; supplementation with cholesterol reversed this effect ${ }^{33}$. In rats, fetal alcohol exposure was associated with changes in the fatty acid and cholesterol composition in the brain which was found to persist into adulthood ${ }^{34}$.

\section{Neonatal Factors}

The neonatal genetics play a very important role in their cholesterol levels. Neonates confirmed to have heterozygous familial hypercholesterolemia via DNA testing showed significant increases in cord cholesterol levels at birth and even greater difference by one year ${ }^{35}$. Neonates with familial hypercholesterolemia were also found to have increased rate of synthesis of lanosterol, squalene, and other cholesterol precursors; interestingly, neonates born to mothers with familial hypercholesterolemia tended to have accelerated cholesterol synthesis at birth compared to those born to fathers with familial hypercholesterolemia ${ }^{36}$. Even short-term elevations in cholesterol have resulted in fatty streaks in the aorta of the neonate. This fatty streak deposit can persist into adolescence resulting in a stiffened aorta ${ }^{5}$.

In addition to cholesterol levels, triglycerides and HDL cholesterol play important roles in the development of atherosclerosis and cardiovascular disease. Children with increased triglyceride to HDL cholesterol ratio were found to have stiffened arterial walls ${ }^{37}$. The CARITALY study of cardiovascular risk factors found that triglyceride to HDL cholesterol ratio had better discrimination of cardiometabolic risk factors in children and adolescents than using total non-HDL cholesterol ${ }^{38}$.

\section{How to diagnose?}

The American Association of Pediatrics (AAP) currently recommends that all children between the ages of 9 and 11 be screened for dyslipidemia for the first time. Additionally, it recommends that the following groups of children be screened between the ages of 2 and 10: children whose parents or grandparents have a history of heart disease or atherosclerosis, children whose parents or grandparents have total blood cholesterol levels of over $240 \mathrm{mg} / \mathrm{dL}$, or those whose family background is not known ${ }^{4}$. This age range was selected for two reasons: this is around the time that the effects of atherosclerosis appear at a higher rate, and is also before the natural decline of LDL-C levels that is seen during puberty ${ }^{39}$.

While not currently in professional guidelines for screening, DNA testing is available for familial hypercholesterolemia and other lipid abnormalities. Two such genetic tests for familial hypercholesterolemia using next generation sequencing include Progenika assessing six genes including LDLR, APOB, PCSK9, APOE, STAP1 and LDLRAP1, boasting 1600 variants of the disease identified and Invitae assessing LDLR, APOB, PCSK9, and LDLRAP $1^{40,41}$. The higher costs of genetic testing, compared to lipid methods, make it unclear if this is a cost effective method at this time.

There may be other limitations to DNA testing in familial hypercholesterolemia. The LOVD database has recorded over 1700 variants of the LDLR gene alone ${ }^{42}$. In a UK based study, approximately $60 \%$ of patients diagnosed with $\mathrm{FH}$ were mutation-negative with genetic testing; this was despite $52 \%$ of mutation negative patients in the top 3 deciles for LDL-C gene scoring. This suggests more complicated polygenic causes for hypercholesterolemia limiting the efficiency of current DNA approaches ${ }^{43}$. A cascade study involving relatives of known familial hypercholesterolemia patients found that approximately $50 \%$ of patients with familial hypercholesterolemia met clinical guidelines for lipid levels for diagnosis of the disorder; the genetic testing used in this group was found to have a sensitivity of $46.2 \%$ with a specificity of $88.0 \%$ compared to lipid methods ${ }^{44}$.

Current diagnosis guidelines in the United States rely heavily on cholesterol levels and known family history. A study conducted testing the MEDPED criteria found that the lipid levels had $98 \%$ specificity, and $87 \%$ sensitivity in adults $^{45}$. Pediatric guidelines proposed by National Lipid Association Expert Panel on Familial Hypercholesterolemia indicate for further screening if LDL is greater than 160 $\mathrm{mg} / \mathrm{dl}$ or non-HDL is over $190 \mathrm{mg} / \mathrm{dl}$; approximately $80 \%$ specificity is achieved when LDL levels are greater than $190 \mathrm{mg} / \mathrm{dl}^{46}$.

\section{What modifications can be used to treat?}

\section{Diet}

Lifestyle changes remain the first step in addressing elevated pediatric cholesterol levels, including a recommendation for referral to a dietician for initial management ${ }^{47}$. Children fed a plant based, no added fat diet for 4 weeks showed decreased body mass index, decreased total and LDL cholesterol levels, decreased systolic blood pressure, and decreased C-reactive protein levels compared to their baseline ${ }^{48}$. A study of children with hypercholesterolemia fed an enriched diet with plant sterols showed a decrease in LDL of $13 \%$ with no changes 
in other serum biochemical or hormonal markers ${ }^{49}$. A diet with cereals enhanced with psyllium fiber was found to decrease cholesterol levels by $7 \%$ in patients with hypercholesterolemia ${ }^{50}$.

\section{Exercise}

An analysis of several studies comparing normal intensity aerobic, high intensity aerobic, and resistance training found positive effects on lipid profiles. Regular aerobic exercise elevated HDL cholesterol by $4.6 \%$ and decreased triglycerides by 3.7\%; high intensity aerobic exercise additionally reduced LDL cholesterol by $12.8 \%$. Resistance training also was effective at reducing LDL cholesterol reducing levels by as much as $14.0 \%$ under supervised training. The addition of resistance training to an aerobic exercise regimen could actually enhance the cholesterol control $^{51}$.

\section{Stress Management}

Stress management strategies including yoga, breathing exercises, meditation, and progressive muscle relaxation were shown to improve weight management and lower triglycerides. Total cholesterol/HDL ratio was decreased for males who adhered to a stress management routine. Diabetic patients that followed a stress management routine showed a decreased hemoglobin $A 1 C^{52}$.

\section{Medications}

Medical intervention should be started for patients $\geq 10$ years of age with cholesterol $\geq 190 \mathrm{mg} / \mathrm{dl}$ where $>6$ months of lifestyle intervention has failed or $\geq 160 \mathrm{mg} / \mathrm{dl}$ with positive family history of cardiovascular disease or positive risk factors for development of cardiovascular disease, where $>6$ months of lifestyle intervention has failed. Statin use is generally regarded as the first line medication regimen for pediatric patients with substantially elevated non-HDL cholesterol levels after diet and exercise. A bile acid sequestrant is also recommended as possible therapy in this population, alone or in combination with statins ${ }^{47}$.

Statins: Many of the statin drugs (HMG CoA Reductase Inhibitor) are FDA approved for use in children with heterozygous FH. Pravastatin (Pravachol) and rosuvastatin (Crestor) are approved for use in patients 8 years and older (post-menarcheal) while atorvastatin (Lipitor), fluvastatin (Lescol), and simvastatin (Zocor) are approved for use from age 10 years (post-menarcheal) ${ }^{53-57}$.

In astudy of pediatric male familial hypercholesterolemia patients treated with lovastatin, LDL-C levels were decreased by 21 to $36 \%$, while HDL-C was increased by $4 \%{ }^{58}$. Another such study on pediatric male patients found a reduction in cholesterol maintained at $25 \%$ at 48 weeks duration ${ }^{59}$. Additionally, a study involving post menarcheal female pediatric patients confirmed LDL-C decreased by
23-27\%. No clinical adverse events or changes in hormones and sexual maturity were noted, however one study showed an increase in aspartate aminotransferase $\mathrm{e}^{58-60}$.

Similarly a two year, double blinded study found that pravastatin had a LDL-C lowering impact of $24.1 \%$ for LDL-R, and a decrease in overall carotid intima change during the duration of the trial. No differences were noted between the control and test group for growth, enzyme, or hormone levels ${ }^{61}$.

One major shortcoming to these statin studies are the relatively short durations, leaving long term impact unclear.

Bile Sequestrants: Colesevelam (Welchol) is approved for use from age 10 years (post-menarchal) ${ }^{62}$. A trial using Colesevelam on pediatric patients between 10 and 17 years old found decreases in LDL-C by $7 \%$ at $1.875 \mathrm{~g}$ and $12 \%$ at a dose of $3.75 \mathrm{~g}$. Nasopharyngitis, upper respiratory tract infection, and headache were reported during the study ${ }^{63}$. In conjunction with a low fat diet, low dose colestipol was found to decrease LDL-C by $19.5 \%$ in a pediatric trial of ages 10-17. While patient growth was not impacted, serum levels of several vitamins including $\mathrm{D}$ and folate were reduced compared to control ${ }^{64}$. Cholesterymine used by patients age 6-11 years found a reduction in LDL-C of $16.9 \%$. Similarly, while growth factors did not appear to be impacted, some serum vitamin levels including $\mathrm{D}$ and folate were found to be reduced compared to control ${ }^{65}$.

Cholesterol Absorption Inhibitor: Ezetimibe (Zetia) has been evaluated for use in the pediatric population along with a statin regimen ${ }^{66}$. Ezetimibe is a cholesterol absorption inhibitor which prevents uptake of dietary cholesterol. Guidelines suggest ezetimibe use can be considered as an add on therapy in familial hypercholesterolemia patients when cholesterol levels are not sufficiently reduced by statin therapy ${ }^{47}$. In a study of familial hypercholesterolemia children and adolescents, cholesterol levels were decreased from 7.3 to $5.7 \mathrm{mmol} / \mathrm{L}$ with use of ezetimibe with no reported adverse effects ${ }^{67}$.

PCSK9 Inhibitors: Alirocumab (Praluent) and Evolocumab (Repatha) are monoclonal antibodies against proprotein convertase subtilisin kexin type 9 (PCSK9). PCSK9 is thought to bind to the LDL receptor encouraging its degradation. By inhibiting degradation, these drugs increase the number of LDL receptors available on the hepatocyte which decreases circulating levels of LDL cholesterol. These drugs are currently approved for use in adults with heterozygous familial hypercholesterolemia who are currently using diet and the maximally tolerated statin dose but still require additional decrease in cholesterol. Additionally, evolocumab is labeled for use in cases of homozygous familial hypercholesterolemia. The effect of these drugs on cardiovascular health have not yet been established ${ }^{68,69}$. In trials evolocumab showed a $57 \%$ 
reduction in LDL cholesterol levels and alirocumab a $61 \%$ reduction ${ }^{70,71}$. Safety and efficacy of these drugs in children are still being evaluated ${ }^{72,73}$.

\section{What else can be done?}

\section{Neonatal Screening by Lipid Approach with Earlier Intervention}

While it is clear that the maternal cholesterol is transported, it is not clear if this transport results in altered lipid profiles in the neonate. After all, one would expect that if the maternal levels impact the neonatal levels that the results may not have utility in neonatal screening and diagnosis. In cases where maternal lipid levels were altered, there appeared to be no significant difference in the cholesterol or triglyceride levels of the neonate ${ }^{74,75}$. In fact, fetal cholesterol levels in the first 6 months of gestation appear to correlate with maternal cholesterol levels, whereas older than 6 months there is no longer a correlation with maternal levels. Additionally, the fetal cholesterol levels were found to be inversely correlated with gestational age ${ }^{6}$. It has even been shown that neonates with confirmed familial hypercholesterolemia via DNA testing had elevated cholesterol levels at birth ${ }^{35}$.

It might seem strange to screen and diagnose at the neonatal stage when medications are labelled for 8-10 years of age, but even before medications become a factor, lifestyle interventions can be implemented. Encouraging a plant-based diet in children has been shown to help manage weight, decrease LDL cholesterol, and decrease blood pressure ${ }^{48}$. Exercise has been shown to improve lipid profiles in children and adolescents ${ }^{51}$. Stress management has been linked to improved weight management, lowered triglycerides, and increased control of diabetes ${ }^{52}$.

\section{References}

1. Benjamin EJ, Blaha MJ, Chiuve SE, et al. Heart Disease and Stroke Statistics-2017 Update: A Report From the American Heart Association. Circulation. 2017 Mar 7; 135(10): e146-603.

2. Ogden CL, Carroll MD, Kit BK, et al. Prevalence of Obesity and Trends in Body Mass Index Among US Children and Adolescents, 1999-2010. JAMA. 2012 Feb 1; 307(5): 483-90.

3. Peter PT, Danielle P, Eileen EM. Prevalence of lipid abnormalities in the United States: The National Health and Nutrition Examination Survey 2003-2006- ClinicalKey. J Clin Lipidol. 2012 Jul 1; 6(4): 325-30.

4. EXPERT PANEL ON INTEGRATED GUIDELINESFOR CARDIOVASCULAR HEALTH AND RISK REDUCTION IN CHILDREN AND ADOLESCENTS. Expert Panel on Integrated Guidelines for Cardiovascular Health and Risk Reduction in Children and Adolescents: Summary Report. PEDIATRICS. 2011 Dec 1; 128(Supplement): S213-56.

5. Lewandowski AJ, Lazdam M, Davis E, et al. 59 Short term elevation of cholesterol level in neonatal life and long term changes in aortic stiffness: insights from use of intravenous lipids. Heart. 2011 Jun 1; 97(Suppl 1): A37-8.

6. Napoli C, D'Armiento FP, Mancini FP, et al. Fatty streak formation occurs in human fetal aortas and is greatly enhanced by maternal hypercholesterolemia. Intimal accumulation of low density lipoprotein and its oxidation precede monocyte recruitment into early atherosclerotic lesions. J Clin Invest. 1997 Dec 1; 100(11): 2680-90.

7. Stefulj J, Panzenboeck U, Becker T, et al. Human Endothelial Cells of the Placental Barrier Efficiently Deliver Cholesterol to the Fetal Circulation via ABCA1 and ABCG1. Circ Res. 2009 Feb 12; 104(5): 600-8.

8. Lindegaard ML, Wassif CA, Vaisman B, et al. Characterization of placental cholesterol transport: ABCA1 is a potential target for in utero therapy of Smith-Lemli-Opitz syndrome. Hum Mol Genet. 2008 Dec 1; 17(23): 3806-13.

9. Zeljkovic A, Vekic J, Spasic S, et al. Changes in LDL and HDL Subclasses in Normal Pregnancy and Associations with Birth Weight, Birth Length and Head Circumference. Matern Child Health J. 2013 Apr 1; 17(3): 556-65.

10. Schreuder YJ, Hutten BA, Van Eijsden M, et al. Ethnic differences in maternal total cholesterol and triglyceride levels during pregnancy: the contribution of demographics, behavioural factors and clinical characteristics. Eur J Clin Nutr Lond. 2011 May; 65(5): 580-9.

11. Bilen O,YashashwiP, Ballantyne CM. Genetic Testing in HyperlipidemiaClinicalKey. Endocrinol Metab Clin. 2016 Mar 1; 45(1): 129-40.

12. de Ferranti SD, Rodday AM, Mendelson MM, et al. Prevalence of Familial Hypercholesterolemia in the 1999 to 2012 United States National Health and Nutrition Examination Surveys (NHANES)CLINICAL PERSPECTIVE. Circulation. 2016 Mar 15; 133(11): 1067-72.

13. Moorjani S, Roy M, Gagné C, et al. Homozygous familial hypercholesterolemia among French Canadians in Québec Province. Arterioscler Thromb Vasc Biol. 1989 Mar 1; 9(2): 211-6.

14. Seftel HC, Baker SG, Jenkins T, et al. Prevalence of familial hypercholesterolemia in Johannesburg Jews. Am J Med Genet. 1989 Dec 1; 34(4): 545.

15. Sowmiya S, Hiremath PB, Kousalya M. Association of hyperlipidemia in preterm delivery. Int J Reprod Contracept Obstet Gynecol. 2017 Feb 9; 4(4): 972-6.

16. Leeson CP, Kattenhorn M, Morley R, et al. Impact of low birth weight and cardiovascular risk factors on endothelial function in early adult life. Circulation. 2001 Mar 6; 103(9): 1264-8.

17. Paz Levy D, Sheiner E, Wainstock T, et al. Evidence that children born at early term (37-38 6/7 weeks) are at increased risk for diabetes and obesity-related disorders. Am J Obstet Gynecol. 2017 Nov 1; 217(5): 588.e1-588.e11.

18. Napoli C, Glass CK, Witztum JL, et al. Influence of maternal hypercholesterolaemia during pregnancy on progression of early atherosclerotic lesions in childhood: Fate of Early Lesions in Children (FELIC) study. Lancet Lond. 1999 Oct 9; 354(9186): 1234-41.

19. Claudio N, Joseph LW, Federico C, et al. Maternal Hypercholesterolemia Enhances Atherogenesis in Normocholesterolemic Rabbits, Which Is Inhibited by Antioxidant or Lipid-Lowering Intervention During Pregnancy: An Experimental Model of Atherogenic Mechanisms in Human Fetuses. J Am Heart Assoc. 2000 Nov 10; 87(10): 946-52.

20. Edison RJ, Muenke M. Central nervous system and limb anomalies in case reports of first-trimester statin exposure. N Engl J Med Boston. 2004 Apr 8; 350(15): 1579-82.

21. Gao F, Wang G, Wang L, et al. Phytosterol nutritional supplement improves pregnancy and neonatal complications of gestational diabetes mellitus in a double-blind and placebo-controlled clinical study. Food Funct. 2017 Jan 26; 8(1): 424-8.

22. DeSisto CL. Prevalence Estimates of Gestational Diabetes Mellitus in the United States, Pregnancy Risk Assessment Monitoring System (PRAMS), 2007-2010. Prev Chronic Dis [Internet]. 2014 [cited 2018 Jan 7]; 11. Available from: https://www.cdc.gov/pcd/ issues/2014/13_0415.htm 
23. Lawrence JM, Contreras R, Chen $\mathrm{W}$, et al. Trends in the prevalence of preexisting diabetes and gestational diabetes mellitus among a racially/ethnically diverse population of pregnant women, 19992005. Diabetes Care. 2008 May; 31(5): 899-904.

24. Evers IM, Valk HW de, Visser GHA. Risk of complications of pregnancy in women with type 1 diabetes: nationwide prospective study in the Netherlands. BMJ. 2004 Apr 15; 328(7445): 915.

25. Day RE, Insley J. Maternal diabetes mellitus and congenital malformation. Survey of 205 cases. Arch Dis Child. 1976 Dec; 51(12): 935-8.

26. Boney CM, Verma A, Tucker R, et al. Metabolic syndrome in childhood: association with birth weight, maternal obesity, and gestational diabetes mellitus. Pediatrics. 2005 Mar; 115(3): e290-296.

27. Milei J, Ottaviani G, Lavezzi AM, et al. Perinatal and infant early atherosclerotic coronary lesions. Can J Cardiol. 2008 Feb; 24(2): 137-41.

28. Matturri L, Ottaviani G, Lavezzi AM. Early atherosclerotic lesions in infancy: role of parental cigarette smoking. Virchows Arch. 2005 Jul 1; 447(1): 74-80.

29. Aycicek A, Varma M, Ahmet K, et al. Maternal active or passive smoking causes oxidative stress in placental tissue. Eur J Pediatr. 2011 May 1; 170(5): 645-51.

30. PLP Bauman A. How Well Does Epidemiological Evidence Hold For The Relationship Between Smoking and Adverse Obstetric Outcomes in New South Wales. Aust N Z J Obstet Gynaecol. 1997 May; 37(2): 168-73.

31. Jones KL, Smith DW, Ulleland CN, et al. Pattern of malformation in offspring of chronic alcoholic mothers. The Lancet. 1973 Jun 9; 301(7815): 1267-71.

32. Clissman D, Giles S, Brennan D. Embryonic exposure to ethanol reduces cholesterol levels in a chick embryo model of Fetal Alcohol Syndrome. Reprod Toxicol. 2016 Sep; 64: 46.

33. Li YX, Yang HT, Zdanowicz M, et al. Fetal alcohol exposure impairs hedgehog cholesterol modification and signaling. Lab Invest. 2007 Mar; 87(3): 231.

34. Barceló-Coblijn G, Wold LE, Ren J, et al. Prenatal Ethanol Exposure Increases Brain Cholesterol Content in Adult Rats. Lipids. 2013 Nov 1; 48(11): 1059-68.

35. Alpo FV, Hannu T, Kimmo K. Neonatal Diagnosis of Familial Hypercholesterolemia in Newborns Born to a Parent With a Molecularly Defined Heterozygous Familial Hypercholesterolemia. Arterioscler Thromb Vasc Biol. 1997 Nov; 17(11): 3332-7.

36. Vuorio AF, Miettinen TA, Turtola $\mathrm{H}$, et al. Cholesterol metabolism in normal and heterozygous familial hypercholesterolemic newborns. J Lab Clin Med. 2002 Jul; 140(1): 35-42.

37. Urbina EM, Khoury PR, McCoy CE, et al. Triglyceride to HDL-C Ratio and Increased Arterial Stiffness in Children, Adolescents, and Young Adults. Pediatrics. 2013 Apr 1; 131(4): e1082-90.

38. Di Bonito P, Valerio G, Grugni G, et al. Comparison of non-HDLcholesterol versus triglycerides-to-HDL-cholesterol ratio in relation to cardiometabolic risk factors and preclinical organ damage in overweight/obese children: The CARITALY study. Nutr Metab Cardiovasc Dis. 2015 May 1; 25(5): 489-94.

39. Stephen RD. Pediatric guidelines for dyslipidemia- ClinicalKey. J Clin Lipidol. 2015 Sep 1; 9(5): S5-10.

40. Progenika North America - SEQPRO LIPO IS [Internet]. [cited 2017 Dec 29]. Available from: http://www.progenika.com/north_america/ index.php?option=com_content\&task=view\&id=325\&Itemid=415

41. Invitae Catalog | Cardiology [Internet]. [cited 2017 Sep 20]. Available from: https://www.invitae.com/en/physician/category/ CAT000001/\#category-content-CAT000010
42. LDLR gene homepage - Shared database [Internet]. [cited $2017 \mathrm{Sep}$ 20]. Available from: https://databases.lovd.nl/shared/genes/LDLR

43. Talmud PJ, Shah S, Whittall R, et al. Use of low-density lipoprotein cholesterol gene score to distinguish patients with polygenic and monogenic familial hypercholesterolaemia: a case-control study. Lancet Lond. 2013 Apr 13; 381(9874): 1293-301.

44. Leren TP, Finborud TH, Manshaus TE, et al. Diagnosis of Familial Hypercholesterolemia in General Practice Using Clinical Diagnostic Criteria or Genetic Testing as Part of Cascade Genetic Screening. Community Genet Basel. 2008 Jan; 11(1): 26-35.

45. Williams RR, Hunt SC, Schumacher MC, et al. Diagnosing heterozygous familial hypercholesterolemia using new practical criteria validated by molecular genetics. Am J Cardiol. 1993 Jul 15; 72(2): 171-6.

46. Goldberg AC, Hopkins PN, Toth PP, etal. Familial Hypercholesterolemia: Screening, diagnosis and management of pediatric and adult patients. J Clin Lipidol. 2011 May; 5(3): 133-40.

47. Daniels SR, Benuck I, Christakis DA, et al. Integrated Guidelines for Cardiovascular Health and Risk Reduction in Children and Adolescents: Summary Report | National Heart, Lung, and Blood Institute [Internet]. 2012 [cited 2018 Jan 4]. Available from: https:// www.nhlbi.nih.gov/node/80308

48. Macknin M, Kong T, Weier A, et al. Plant-Based, No-Added-Fat or American Heart Association Diets: Impact on Cardiovascular Risk in Obese Children with Hypercholesterolemia and Their Parents. J Pediatr. 2015 Apr 1; 166(4): 953-959.e3.

49. Garoufi A, Vorre S, Soldatou A, et al. Plant sterols-enriched diet decreases small, dense LDL-cholesterol levels in children with hypercholesterolemia: a prospective study. Ital J Pediatr [Internet]. 2014 May 3 [cited 2018 Jan 6]; 40(1). Available from: http://go.galegroup.com. ezproxy2.library.drexel.edu/ps/pdfGenerator?tabID=\&actionCmd=DO_DOWNLOAD_DOCUMENT\&docId=GALE\%7CA459649659\&userGroupName=drexel_main\&inPS=true\&prodId=AONE

50. Davidson MH, Dugan LD, Burns JH, et al. A psyllium-enriched cereal for the treatment of hypercholesterolemia in children: a controlled, double-blind, crossover study. Am J Clin Nutr. 1996 Jan; 63(1): 96102.

51. Mann S, Beedie C, Jimenez A. Differential Effects of Aerobic Exercise, Resistance Training and Combined Exercise Modalities on Cholesterol and the Lipid Profile: Review, Synthesis and Recommendations. Sports Med Auckl. 2014 Feb; 44(2): 211-21.

52. Daubenmier JJ, Weidner G, Sumner MD, et al. The Contribution of Changes in Diet, Exercise, and Stress Management to Changes in Coronary Risk in Women and Men in the Multisite Cardiac Lifestyle Intervention Program. Ann Behav Med N Y. 2007 Feb; 33(1): 57-68.

53. PRAVACHOL - pravastatin sodium [package insert]. Princeton, NJ: Bristol-Myer Squibb Company. 1991. [Internet]. [cited 2018 Jan 3]. Available from: https://packageinserts.bms.com/pi/pi_pravachol.pdf

54. CRESTOR - rosuvastatin calcium [package insert] Wilmington, Delaware: AstraZenica Pharmaceuticals LP. 2003. [Internet]. [cited 2018 Jan 3]. Available from: https://www.azpicentral.com/crestor/ crestor.pdf\# page $=1$

55. LIPITOR-atorvastatin calcium trihydrate tablet. [package insert] , New York, New York: Parke-Davis, a Division of Pfizer Inc. 1996. [Internet]. [cited 2018 Jan 3]. Available from: http://labeling.pfizer. com/ShowLabeling.aspx?id=587

56. LESCOL - fluvastatin sodium [package insert]. East Hanover, New Jersey: Novartis Pharmaceuticals Corporation. 1993. [Internet]. [cited 2018 Jan 3]. Available from: https://www.pharma.us.novartis.com/ sites/www.pharma.us.novartis.com/files/Lescol.pdf

57. ZOCOR - simvastatin [package insert]. Whitehouse Station, NJ: Merck \& Co., INC. 1999. [Internet]. [cited 2018 Jan 3]. Available from: https:// www.merck.com/product/usa/pi_circulars/z/zocor/zocor_pi.pdf 
58. Lambert M, Lupien PJ, Gagné C, et al. Treatment of familial hypercholesterolemia in children and adolescents: effect of lovastatin. Canadian Lovastatin in Children Study Group. Pediatrics. 1996 May; 97(5): 619-28.

59. Stein EA, Illingworth DR, Kwiterovich PO, et al. Efficacy and safety of lovastatin in adolescent males with heterozygous familial hypercholesterolemia: a randomized controlled trial. JAMA. 1999 Jan 13; 281(2): 137-44.

60. Clauss SB, Holmes KW, Hopkins P, et al. Efficacy and safety of lovastatin therapy in adolescent girls with heterozygous familial hypercholesterolemia. Pediatrics. 2005 Sep; 116(3): 682-8.

61. Wiegman A, Hutten BA, de Groot E, et al. Efficacy and safety of statin therapy in children with familial hypercholesterolemia: a randomized controlled trial. JAMA. 2004 Jul 21; 292(3): 331-7.

62. WELCHOL - colesevelam hydrochloride [packet insert]. Parsippany, New Jersey. Daiichi Sankyo, Inc. 2000. [Internet]. [cited 2018 Jan 5]. Available from: http://dsi.com/prescribing-information-portlet/ getPIContent?productName=Welchol\&inline $=$ true

63. Stein EA, Marais AD, Szamosi T, et al. Colesevelam Hydrochloride: Efficacy and Safety in Pediatric Subjects with Heterozygous Familial Hypercholesterolemia. J Pediatr. 2010 Feb 1; 156(2): 231-236.e3.

64. Tonstad S, Sivertsen M, Aksnes L, et al. Low dose colestipol in adolescents with familial hypercholesterolaemia. Arch Dis Child. 1996 Feb; 74(2): 157-60.

65. Tonstad S, Knudtzon J, Sivertsen M, et al. Efficacy and safety of cholestyramine therapy in peripubertal and prepubertal children with familial hypercholesterolemia. J Pediatr. 1996 Jul 1; 129(1): 42-9.

66. ZETIA - ezetimibe [package insert] Whitehouse Station, NJ: Merck \& Co., INC. 2002. [Internet]. [cited 2018 Feb 26]. Available from: https:// www.merck.com/product/usa/pi_circulars/z/zetia/zetia_pi.pdf

67. Clauss S, Wai KM, Kavey REW, et al. Ezetimibe Treatment of Pediatric
Patients with Hypercholesterolemia. J Pediatr. 2009 Jun 1; 154(6): 869-72.

68. Praluent - Alirocumab [package insert]. Bridgewater, NJ. Regeneron, a Sanofi company. 2015. [Internet]. [cited 2018 Jul 15]. Available from: https://www.accessdata.fda.gov/drugsatfda_docs/ label/2015/1255590rig1s000lbledt.pdf

69. Rapatha - Evolocumab [Package Insert]. Thousand Oaks, CA. Amgen. 2015. [Internet]. [cited 2018 Jul 15]. Available from: https://www. accessdata.fda.gov/drugsatfda_docs/label/2015/125522s000lbl.pdf

70. Blom DJ, Hala T, Bolognese M, et al. A 52-Week Placebo-Controlled Trial of Evolocumab in Hyperlipidemia. N Engl J Med Boston. 2014 May 8; 370(19): 1809-19.

71. Robinson JG, Farnier M, Krempf M, et al. Efficacy and Safety of Alirocumab in Reducing Lipids and Cardiovascular Events. N Engl J Med Boston. 2015 Apr 16; 372(16): 1489-99.

72. Open Label Study to Evaluate Safety, Tolerability and Efficacy of Evolocumab (AMG 145) in Pediatric Subjects (10 to 17 Years of Age) With Heterozygous Familial Hypercholesterolemia (HeFH) or Homozygous Familial Hypercholesterolemia (HoFH). - Full Text View - ClinicalTrials.gov [Internet]. [cited 2018 Jul 15]. Available from: https://clinicaltrials.gov/ct2/show/NCT02624869

73. An Efficacy and Safety Study of Alirocumab in Children and Adolescents With Heterozygous Familial Hypercholesterolemia - Full Text View - ClinicalTrials.gov [Internet]. [cited 2018 Jul 15]. Available from: https://clinicaltrials.gov/ct2/show/NCT03510884

74. Sales WB, Silleno Junior JD, Kroll C, et al. Influence of altered maternal lipid profile on the lipid profile of the newborn. Arch Endocrinol Metab. 2015 Apr 1; 59(2): 123.

75. Khoury J, Henriksen T, Christophersen B, et al. Effect of a cholesterollowering diet on maternal, cord, and neonatal lipids, and pregnancy outcome: A randomized clinical trial. Am J Obstet Gynecol. 2005 Oct 1; 193(4): 1292-301. 